\title{
Correction to: The modulation of Indian summer monsoon onset processes during ENSO through equatorward migration of the subtropical jet stream
}

\author{
Devanil Choudhury ${ }^{1,2} \cdot$ Debashis Nath ${ }^{3,4} \cdot$ Wen Chen $^{1}$
}

Published online: 23 March 2021

๑) Springer-Verlag GmbH Germany, part of Springer Nature 2021

\section{Correction to: Climate Dynamics}

https://doi.org/10.1007/s00382-021-05700-4

In the original version of the article, there is a diagonal line in figures 1, 3 and 4. The correct Fig. 1, Fig. 3 and Fig. 4 is given below,

Debashis Nath

nathd@mail.sysu.edu.cn; debashis.narl@gmail.com

1 Center for Monsoon System Research, Institute of Atmospheric Physics, Chinese Academy of Sciences, Beijing, China

2 College of Earth and Planetary Science, University of Chinese Academy of Science, Beijing, China

3 School of Atmospheric Sciences, Sun Yat-sen University, Zhuhai, China

4 Guandong Province Key Laboratory for Climate Change and Natural Disaster Studies, Sun Yat-sen University, Zhuhai, China 


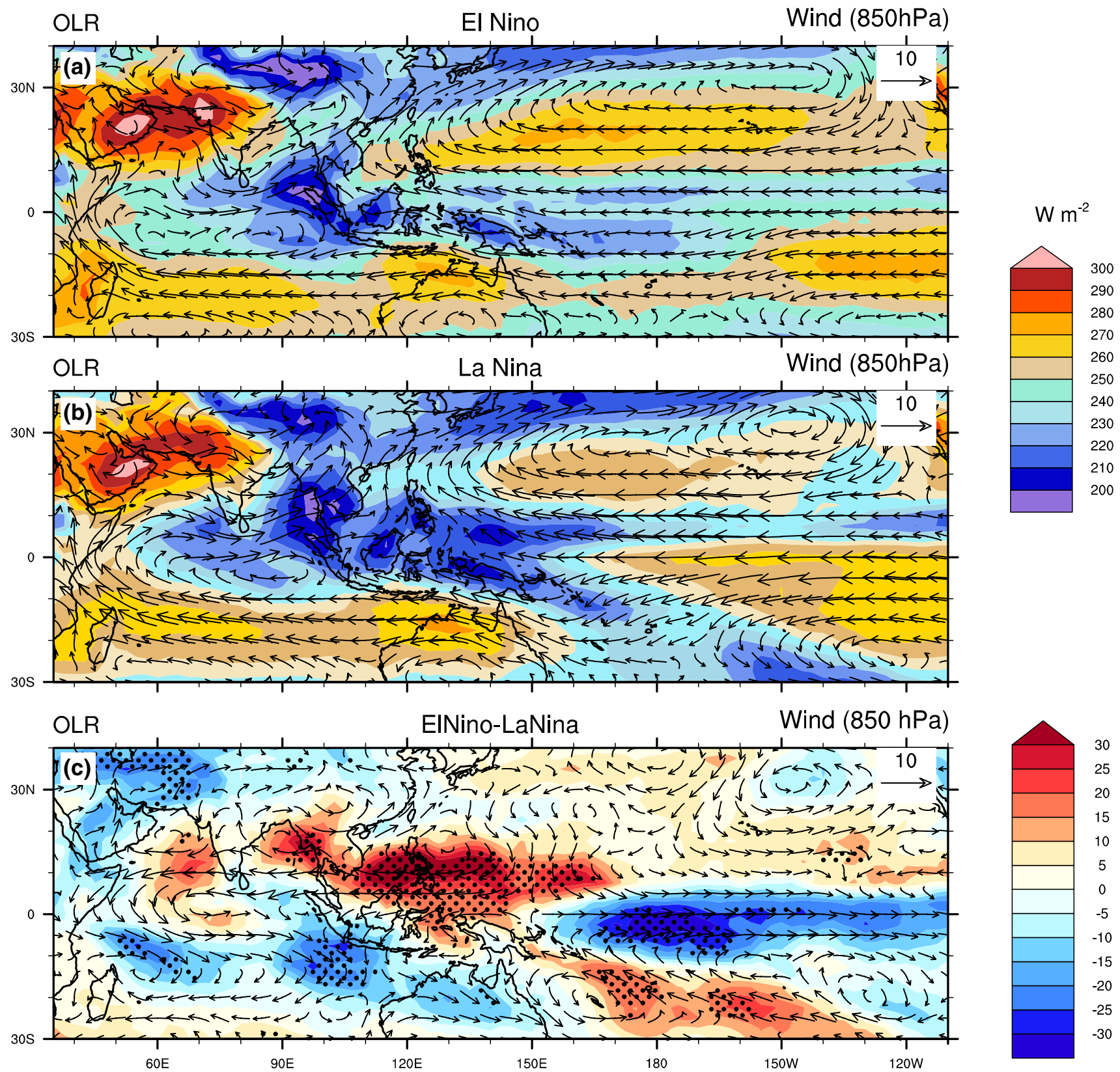

Fig. 1 Composite May mean OLR (shaded, $\left.\mathrm{W} \mathrm{m}^{-2}\right)$ and wind at $850 \mathrm{hPa}\left(\mathrm{m} \mathrm{s}^{-1}\right)$ for a El Niño, b La Niña, their differences $\mathbf{c}$ El Niño-La Niña. In OLR difference (c), dots indicate area significant at $95 \%$ confidence level based on a two tailed $t$-test 


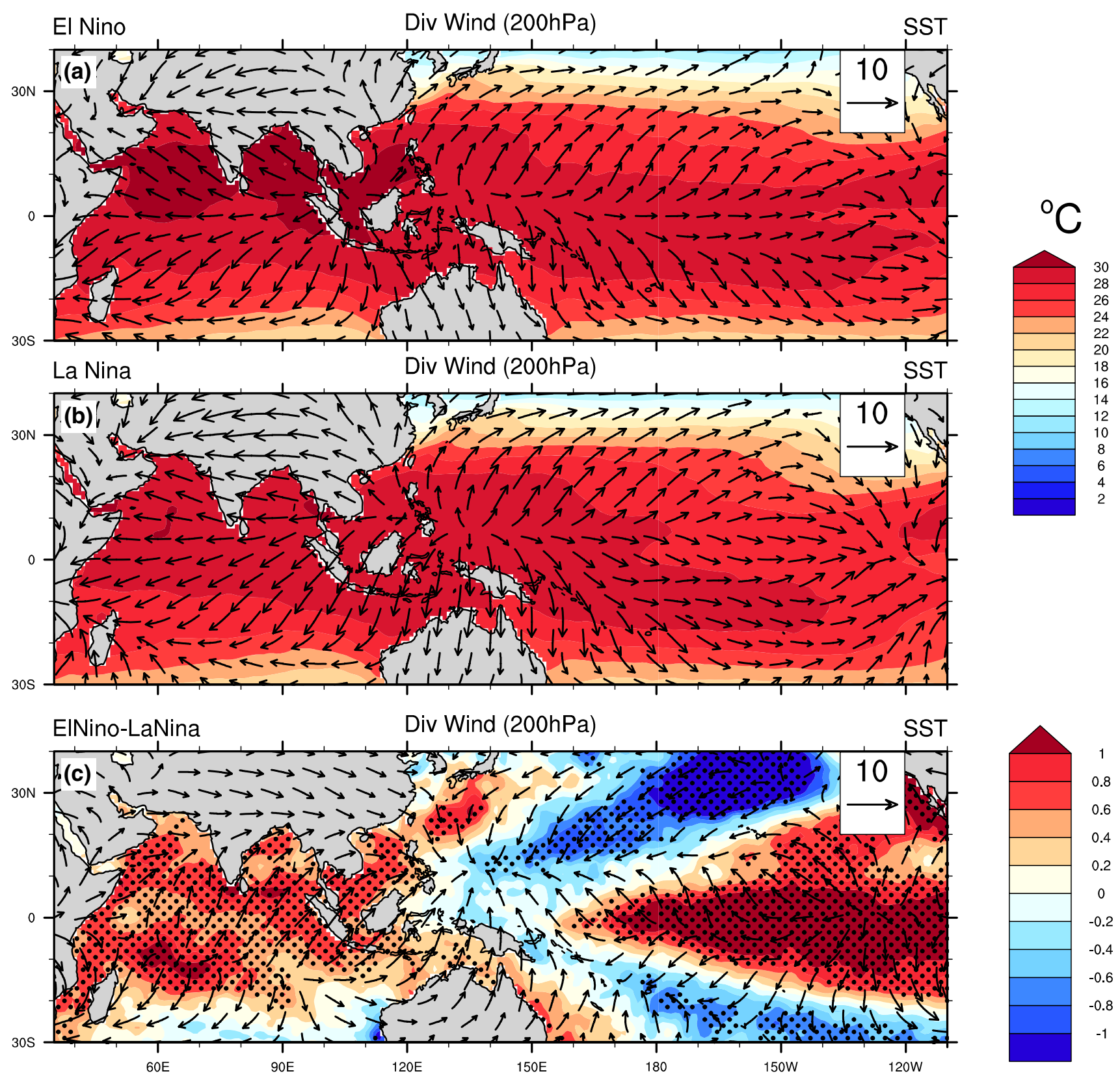

Fig. 3 Composite May mean SST (shaded, ${ }^{\circ} \mathrm{C}$ ) and divergent wind at $200 \mathrm{hPa}\left(\mathrm{ms}^{-1}\right)$ for a El Niño, b La Niña, their differences c El Niño-La Niña. In SST difference, dots indicate area significant at $95 \%$ confidence level based on a two tailed $t$-test 


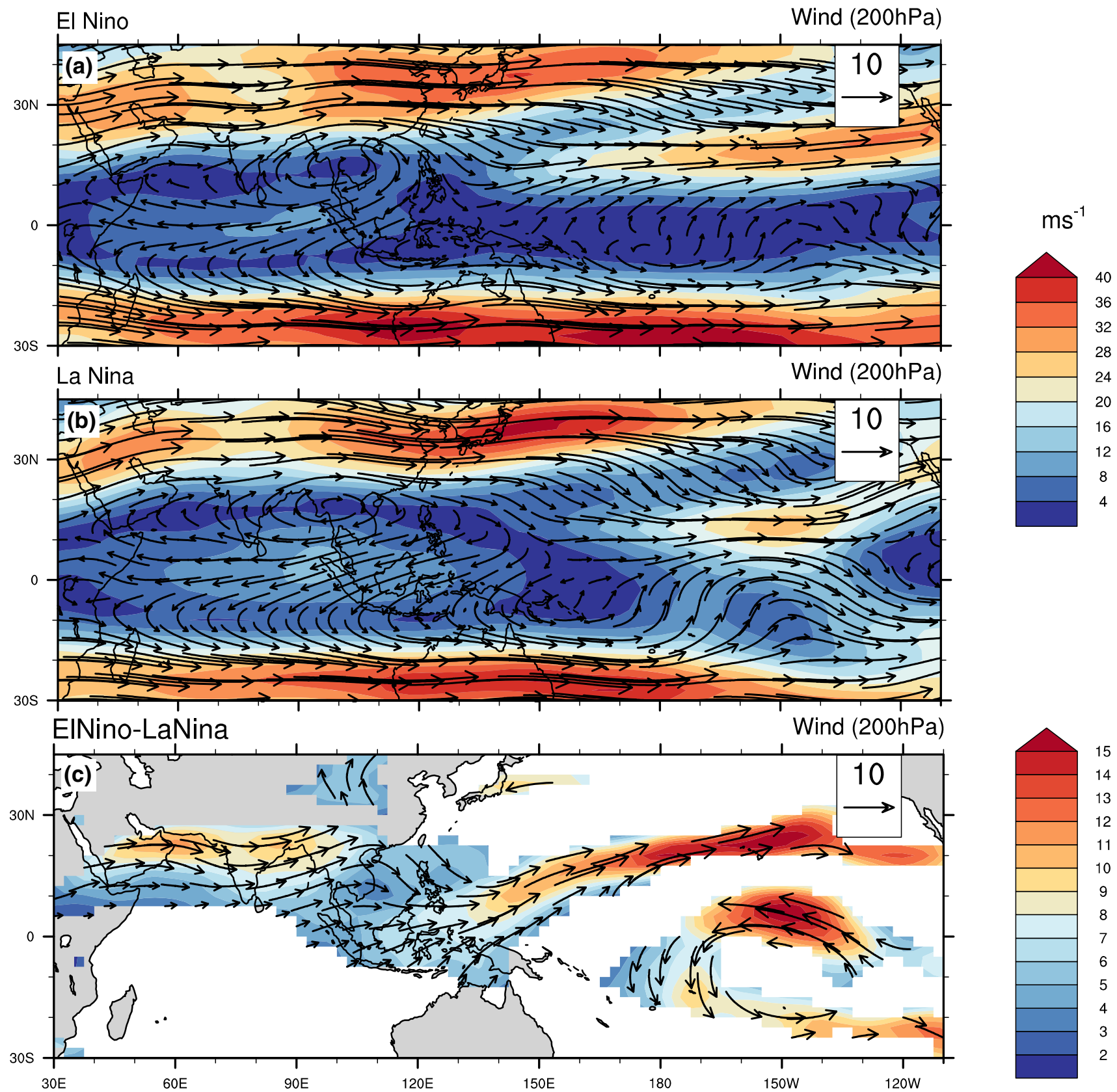

Fig. 4 Composite May mean wind at $200 \mathrm{hPa}\left(\mathrm{m} \mathrm{s}^{-1}\right)$ for a El Niño, b La Niña, their differences c El Niño-La Niña. In wind difference, only winds significant at $95 \%$ confidence level based on a two tailed $t$-test are plotted

The original article has been corrected.

Publisher's Note Springer Nature remains neutral with regard to jurisdictional claims in published maps and institutional affiliations. 